\title{
The between and within day variation in gross efficiency
}

\author{
Dionne A. Noordhof · Jos J. de Koning • \\ Teun van Erp · Bart van Keimpema • \\ Daan de Ridder $\cdot$ Ruby Otter $\cdot$ Carl Foster
}

Accepted: 13 April 2010/Published online: 13 May 2010

(C) The Author(s) 2010. This article is published with open access at Springerlink.com

\begin{abstract}
Before the influence of divergent factors on gross efficiency (GE) [the ratio of mechanical power output (PO) to metabolic power input (PI)] can be assessed, the variation in GE between days, i.e. the test-retest reliability, and the within day variation needs to be known. Physically active males $(n=18)$ performed a maximal incremental exercise test to obtain $V \mathrm{O}_{2 \max }$ and $\mathrm{PO}$ at $V \mathrm{O}_{2 \max }\left(\mathrm{PVO}_{2 \max }\right)$, and three experimental testing days, consisting of seven submaximal exercise bouts evenly distributed over the $24 \mathrm{~h}$ of the day. Each submaximal exercise bout consisted of six min cycling at 45,55 and $65 \% \mathrm{PVO}_{2 \max }$, during which $V \mathrm{O}_{2}$ and RER were measured. GE was determined from the final 3 min of each exercise intensity with: $\mathrm{GE}=(\mathrm{PO} /$ PI) $\times 100 \%$. PI was calculated by multiplying $\mathrm{VO}_{2}$ with the oxygen equivalent. GE measured during the individually highest exercise intensity with RER $<1.0$ did not differ significantly between days $(F=2.70, p=0.08)$, which resulted in lower and upper boundaries of the $95 \%$ limits of agreement of 19.6 and $20.8 \%$, respectively, around a mean GE of $20.2 \%$. Although there were minor within day variations in GE, differences in GE over the day were not significant $(F=0.16, p=0.99)$. The measurement of GE during cycling at intensities approximating VT is apparently very robust, a change in GE of $\sim 0.6 \%$ can be reliably
\end{abstract}

Communicated by Klaas Westerterp.

D. A. Noordhof $(\varangle)$. J. J. de Koning · T. van Erp .

B. van Keimpema - D. de Ridder - R. Otter - C. Foster

Department of Human Movement Sciences,

VU University-Amsterdam, Van Der Boechorststraat 9, 1081 BT Amsterdam, The Netherlands

e-mail: d.noordhof@fbw.vu.nl

C. Foster

University of Wisconsin-La Crosse, La Crosse, USA detected. Lastly, GE does not display a circadian rhythm so long as the criteria of a steady-state $V \mathrm{O}_{2}$ and RER $<1.0$ are applied.

Keywords Reliability - Diurnal variation ·

Circadian rhythm $\cdot$ Aerobic metabolism

\section{Introduction}

Gross efficiency (GE) [the ratio of mechanical power output (PO) to metabolic power input (PI) (van Ingen Schenau and Cavanagh 1990)] is an important factor in performance (Joyner 1991; Joyner and Coyle 2008) and in the use of energy flow models (de Koning et al. 1999, 2005). Hettinga et al. (2007) showed that a change in GE of only $0.9 \%$ could result in a $25.6 \mathrm{~s}$ difference in time over a $20 \mathrm{~km}$ cycling time trial. Additionally, differences in GE (or its equivalent, running economy) have been shown to account for differences in cycling (Lucia et al. 2002) and running (Foster and Lucia 2007; Ingham et al. 2008) performance, particularly in athletes matched for high $V \mathrm{O}_{2 \max }$. However, for the proper use of energy flow models and for the interpretation of research findings it is important to have good insight into the magnitude and variation in GE.

Different studies have shown that there are differences in GE between subjects, which could be due to differences in technique or skill (Nickleberry and Brooks 1996; Moseley and Jeukendrup 2001; Hintzy et al. 2005; Hopker et al. 2007) and/or to genetics (Coyle et al. 1991, 1992; Mogensen et al. 2006) of the subjects. Most studies performed on efficiency are cross-sectional in nature and longitudinal studies are needed to study the causal relationship between, for example training and GE. Prior to conducting a longitudinal study it is essential to have good 
insight into the reliability of measuring GE. Moseley and Jeukendrup (2001) determined economy (EC), delta efficiency (DE), and GE on three different occasions, separated by at least 5 days. The within subjects coefficient of variation $(\mathrm{CV})$ was $3.3,6.7$, and $4.2 \%$ for EC, DE, and GE, respectively. Thus, when measuring efficiency on multiple days a smaller variation in GE is expected than in DE. The mean $\mathrm{CV}$ was $3.2 \%$ for $\mathrm{GE}$, which implies that a change in GE as small as $0.6 \%$ (e.g., 20.0-20.6\%) can be perceived (Moseley and Jeukendrup 2001). However, there are some limitations to the study of Moseley and Jeukendrup (2001). The first limitation is that Moseley and Jeukendrup (2001) averaged the oxygen uptake $\left(V \mathrm{O}_{2}\right)$ and RER data over the second and third minute of each 3-min exercise step to determine GE. From previous research it is known that $\mathrm{VO}_{2}$ needs 3 min to reach a steady-state and it is therefore not ideal to average $V \mathrm{O}_{2}$ and RER data over the second and third minute because, $V \mathrm{O}_{2}$ may not be in steady-state (Whipp and Wasserman 1972; Barstow and Molé 1991). The second point of discussion is that Moseley and Jeukendrup (2001) calculated GE as the mean of all breathby-breath data collected in the last 2 min of each exercise intensity step, during which RER did not exceed 1.0. It is well known that GE increases in a curvilinear fashion with an increase in exercise intensity (Ransom et al. 2008; Ettema and Lorås 2009), so the most accurate way to determine GE is to calculate GE from the breath-by-breath data collected at the highest exercise intensity with an RER $<1.0$. Therefore, the purpose of this study was to determine the reliability of GE using some improvements in the research design of Moseley and Jeukendrup (2001).

Besides the variation in GE between days the within day variation in GE also needs to be considered. Circadian (or diurnal) rhythms in resting heart rate (HR) (Faria and Drummond 1982; Giacomoni et al. 1999; Callard et al. 2001), oral temperature (Souissi et al. 2004), mesenteric temperature (Callard et al. 2000), rectal temperature (Deschenes et al. 1998; Giacomoni et al. 1999), blood pressure (Deschenes et al. 1998), and circulating hormones (Deschenes et al. 1998) have been extensively investigated. Body temperature (rectal temperature) shows a circadian rhythm in rest, with a mean amplitude of $0.44^{\circ} \mathrm{C}$ and a mean acrophase at 17:16 h, which persisted at light, moderate and heavy exercise (Reilly and Brooks 1990). However, there are conflicting results about the circadian effect on aerobic exercise capacity. Hill (1996) and Giacomoni et al. (1999) found significant differences in submaximal steady-state $\mathrm{VO}_{2}$ between exercise performed in the morning and in the evening. The aerobic system responded faster (Hill 1996) and reached a greater $V_{2}$ amplitude in the evening (Hill 1996; Giacomoni et al. 1999). This time of day effect on the cardiovascular and respiratory response to exercise can be partly attributed to the circadian rhythm in body temperature (Hill 1996). Subjects performed incremental exercise tests at 08:00, 12:00, 16:00, and 20:00 h randomized over different days, with at least $48 \mathrm{~h}$ between consecutive tests in the study of Deschenes et al. (1998). They found no significant effect of time of day on either pre-exercise or exercise $V_{2}$. These inconclusive results could be due to the chosen time points at which the exercise tests were conducted. In order to determine the circadian rhythms in $\mathrm{VO}_{2}$ and other exercise related variables ideally, exercise bouts should be evenly distributed over $24 \mathrm{~h}$ (Nelson et al. 1979; Souissi et al. 2004). If a circadian rhythm in submaximal $V \mathrm{O}_{2}$ is present, as reported by Hill (1996) and Giacomoni et al. (1999), it would be expected that GE will also vary with time of day. Brisswalter et al. (2007) investigated the effect of time of day on net efficiency (NE) and GE. Subjects performed four submaximal exercise bouts, two in the morning (between 07:00 and 08:30 h) and two in the evening (between 19:00 and 20:30 h), at 80\% of the PO associated with the ventilatory threshold $\left(80 \% \mathrm{PT}_{\text {vent }}\right)$. Exercise bouts were separated by at least $24 \mathrm{~h}$. No significant time of day effect was found in $V \mathrm{O}_{2}, V \mathrm{CO}_{2}$, or RER at rest or during light cycling exercise $(45 \mathrm{~W})$. Nevertheless, when exercise intensity increased to $80 \% \mathrm{PT}_{\text {vent }}$ there was a significantly higher $V \mathrm{O}_{2}$ amplitude and a larger $V \mathrm{O}_{2}$ time constant (slower response) in the morning compared to the evening, resulting in a significantly higher NE in the evening (17.3 vs. $20.5 \%$ ). The difference in GE, $15.1 \%$ (morning) versus $17.1 \%$ (evening), did not reach statistical significance, which agrees in principal with Moseley and Jeukendrup (2001) who found a mean CV in GE of only 3.2\%. The main shortcoming of the study of Brisswalter et al. (2007) is that they did not use the minimum of six exercise bouts evenly distributed over the $24 \mathrm{~h}$ of the day, which is viewed as a critical issue by Nelson et al. (1979). A study that did use six exercise bouts evenly distributed over $24 \mathrm{~h}$ was performed by Reilly and Brooks (1990), who found a significant circadian rhythm at rest in rectal temperature, $\mathrm{HR}, V \mathrm{O}_{2}, V \mathrm{CO}_{2}$ and $\mathrm{VE}$. However, during submaximal exercise no circadian rhythm in $V_{2}, V \mathrm{CO}_{2}, \mathrm{VE}, \mathrm{NE}$, and GE was found. The limitation of the study of Reilly and Brooks (1990) is that NE and GE were determined during exercise at 82 and $147 \mathrm{~W}$, which are relatively low absolute workloads, corresponding to relative workloads of 37 and $56 \% \quad \mathrm{VO}_{2 \max }$. To accurately investigate a possible circadian rhythm in efficiency each subject should exercise at the same relative intensity and multiple exercise intensities should be chosen, in order to be sure that the highest efficiency is reached (Ransom et al. 2008). Because previous research showed that muscle temperature affected efficiency during in vitro measurements (He et al. 2000) and during cycling exercise (Ferguson et al. 2002; Bell and Ferguson 2009) it could be expected that the circadian 
rhythm in body temperature affects GE during cycling exercise.

Therefore, the purpose of this study was to assess the variation in GE between and within days by measuring GE at six time points equally distributed over the $24 \mathrm{~h}$ of the day. When the variation in GE within and between days is known it will be easier to interpret the findings of other studies and to accurately use energy flow models.

\section{Methods}

\section{Subjects}

Eighteen healthy, physically active, males participated in this study. Subjects were characterized by a mean height of $183 \pm 6 \mathrm{~cm}$, a mean body mass of $74 \pm 6 \mathrm{~kg}$, a mean $V O_{2 \max }$ of $61.3 \pm 9.3 \mathrm{ml} \mathrm{kg}^{-1} \mathrm{~min}^{-1}$ and a mean $\mathrm{PO}$ at $V \mathrm{O}_{2 \max }\left(\mathrm{PVO}_{2 \max }\right)$ of $378 \pm 54 \mathrm{~W}$. Subjects gave written informed consent. In addition, subjects completed a health history form in order to make sure that they were physically healthy and completed the Horne and Ostberg's morningness-eveningness self-assessment questionnaire (Horne and Östberg 1976) to evaluate their chronotypes. Eleven of the total of 18 subjects were classified as neither type, four subjects were classified as moderately morning chronotypes and three subjects were moderately evening chronotypes. The experimental protocol for the study was approved by the ethics committee of the Faculty of Human Movement Sciences at the VU University in Amsterdam (The Netherlands).

The subjects refrained from strenuous exercise the day before the testing sessions and followed their normal sleep/ wake cycle. Alcohol was not consumed within $24 \mathrm{~h}$ prior to the tests and caffeine containing beverages were not consumed within $3 \mathrm{~h}$ preceding the beginning of the testing sessions. Neither substance was consumed during the experimental days. All subjects ate their last meal at least $3 \mathrm{~h}$ before the start of the testing session.

\section{Experimental design}

All subjects performed a maximal incremental exercise test at least $24 \mathrm{~h}$ before the first of the three experimental testing days. Each experimental testing day consisted of seven submaximal exercise tests distributed at equidistant time intervals over $24 \mathrm{~h}$. The first and last submaximal exercise test was conducted at the same time of day, separated by $24 \mathrm{~h}$, to assess the effect of a previous day of physical activity. Subjects performed the $24 \mathrm{~h}$ testing days in groups of six subjects. The first two subjects completed their first submaximal exercise test at 10:00 $\mathrm{h}$ and the following tests at 14:00, 18:00, 22:00, 02:00, 06:00, 10:00.
The second pair completed their first submaximal exercise test at $10.30 \mathrm{~h}(14: 30,18: 30,22: 30,02: 30,06: 30,10: 30)$, and the third pair executed their first submaximal exercise test at 11:00 h (15:00, 19:00, 23:00, 03:00, 07:00, 11:00). During the $24 \mathrm{~h}$ testing days the subjects resided in the laboratory, in order to standardize the experimental conditions. Three hours before the first and second submaximal exercise tests subjects consumed a meal, immediately after the third test subjects consumed their dinner, and after the fourth submaximal exercise test subjects were asked to sleep. Fifteen min before the submaximal exercise test at, respectively, 02:00 $\mathrm{AM}$, 02:30 $\mathrm{AM}$, and 03:00 $\mathrm{AM}$ and at, respectively, 06:00 $\mathrm{AM}, 06: 30 \mathrm{AM}$, and 07:00 $\mathrm{AM}$ the subjects woke up, dressed and prepared themselves for the test. After the test in the early morning (06:00 AM, 06:30 $\mathrm{AM}$, 07:00 AM, respectively) subjects consumed their breakfast. After the last submaximal test of each experimental testing day subjects completed the Leeds Sleep Evaluation Questionnaire (LSEQ) in order to get an idea of the effort it took to get to sleep, to wake up, their quality of sleep, and their overall feeling after waking up (Parrott and Hindmarch 1980).

Exercise was performed on an electronically braked cycle ergometer (Excalibur Sport, Lode Medical Technology, Groningen, The Netherlands) at a pedal frequency of 80 revolutions per minute (rpm) (Coast et al. 1986; Foss and Hallén 2005), which was continually displayed on a screen in front of the cyclists. Saddle and handlebar position set to individual preferences were kept the same during all tests. Subjects used their own clipless pedals or toe clips.

Expired air was analyzed breath-by-breath using open circuit spirometry (Cosmed quark $\mathrm{b}^{2}$, Cosmed S. R. L., Rome, Italy). Before the start of each exercise test the gas analyzer was calibrated with room air, and a reference gas mixture $\left(16 \% \mathrm{O}_{2}\right.$ and $\left.5 \% \mathrm{CO}_{2}\right)$ and the volume transducer was calibrated using a 3-L syringe (Cosmed S. R. L., Rome, Italy). HR was measured using radiotelemetry. Before the start and immediately after the exercise test body temperature (BT) was measured with a telemetric gastrointestinal temperature pill (CorTemp, HQInc, Palmetto, FL, USA), because many exercise related variables are closely related to the circadian rhythm in BT (Souissi et al. 2004).

Room temperature $\left(17.4 \pm 2.0^{\circ} \mathrm{C}\right)$ and relative humidity $(54.5 \pm 8.1 \%)$ were standardized in order to keep the environmental conditions relatively the same during all testing sessions.

Maximal incremental exercise test

The maximal incremental exercise test started with a warm-up of $2 \mathrm{~min}$ at a PO of $100 \mathrm{~W}$. Immediately after the 
warm-up the maximal incremental exercise test began at a PO of $100 \mathrm{~W}$ which increased every minute by $25 \mathrm{~W}$. During the test subjects had to maintain a pedal frequency of $80 \mathrm{rpm}$. The test ended when the pedal frequency dropped below the $70 \mathrm{rpm}$. The maximal incremental exercise test was not conducted at a specific time of the day, because previous research has shown that there is no circadian rhythm in $V \mathrm{O}_{2 \max }$ (Reilly and Brooks 1990).

\section{Experimental testing days}

Three hours prior to the start of the first experimental testing day subjects ate their breakfast and ingested the temperature pill. The subjects arrived $1 \mathrm{~h}$ prior to the start of the first exercise test at the laboratory to make sure they were in relative rest.

Resting metabolism was measured during the first 6 min of the submaximal exercise test, while subjects were sitting on the bicycle ergometer. After 6 min of rest, exercise intensity was set at $45 \%$ of $\mathrm{PVO}_{2 \max }$ and the subjects cycled $6 \mathrm{~min}$ at this relatively low exercise intensity, after which the exercise intensity increased to $55 \% \mathrm{PVO}_{2 \max }$ for another 6 min. During the third and last exercise step, the workload increased to $65 \% \mathrm{PVO}_{2 \max }$ which was maintained for the remaining 6 min (Ransom et al. 2008). Just as during the incremental exercise test, pedal frequency was maintained at $80 \mathrm{rpm}$. During the last $30 \mathrm{~s}$ of each submaximal exercise step subjects rated their perceived exertion (Borg 1982). $V \mathrm{O}_{2}$, respiratory exchange ratio (RER), heart rate (HR), and body temperature were measured as previously described.

GE was determined during the 3:00-6:00 interval of each 6-min submaximal exercise step. GE was calculated using Eq. 1:

$\mathrm{GE}=(\mathrm{PO} / \mathrm{PI}) 100 \%$

in which PI is the metabolic PI, which can be calculated by multiplying $\mathrm{VO}_{2}$ with the oxygen equivalent (Eq. 2) as suggested by Garby and Astrup (1987).

$\mathrm{PI}=\frac{V \mathrm{O}_{2}}{60}(4940 \mathrm{RER}+16040)$.

For the determination of $\mathrm{GE} V \mathrm{O}_{2}$ had to be in steady-state and RER $<1.0$, to avoid the contribution of unmeasured anaerobic work (van Ingen Schenau and Cavanagh 1990).

\section{Statistics}

All data is presented as individual values or means \pm standard deviations (SD). A repeated measures ANOVA (14.0, LEAD Technologies, Inc.) was used to determine the variation in $V \mathrm{O}_{2}, \mathrm{GE}, \mathrm{RPE}$, and $\mathrm{BT}$ between days. If significant main effects were found Bonferroni adjustments were used to locate the differences. To assess the variation in GE between days the $95 \%$ limits of agreement and the CV were calculated for each individual (Hopkins 2000). The individual $\mathrm{CV}$ was calculated by expressing the SD as a percentage of the mean and the overall $\mathrm{CV}$ was obtained by taking the square root of the mean of the squared $\mathrm{CVs}$ (Hopkins 2000).

The within day variation in $V \mathrm{O}_{2}, \mathrm{GE}, \mathrm{RPE}$, and $\mathrm{BT}$ was first analyzed using a repeated measures ANOVA. If there was a significant difference in the above mentioned variables within a day a least square Cosinor regression analysis was performed to determine the best fit cosine function, i.e. $Y(t)=M+A \cos (\omega t+\varphi)$ where $t$ is the time of day, $M$ is the mesor (mean value), $A$ is the amplitude (half the variation from peak to trough values), $\varphi$ the acrophase (time of peak), and $\omega$ the angular speed (in the current study the angular speed is one cycle per day) (Souissi et al. 2004). A repeated measures ANOVA, with the factor day (3), was conducted to find out if $A$ was significantly different from zero and to compare the acrophases of the cosine functions of different parameters. The scores on the LSEQ were compared to 50, which is the score that corresponds to a normal night sleep (Lomeli et al. 2007), with a repeated measures ANOVA with the factor day. To test the effect of a previous day of physical activity, the difference in $V \mathrm{O}_{2}, \mathrm{GE}$, and RPE between the first and last submaximal exercise test of an experimental testing day were evaluated using repeated measures ANOVA. Differences were considered to be significant if $p<0.05$.

\section{Results}

All subjects completed the three experimental testing days. One exercise intensity was selected for GE analysis, based on the mean RER during the final 3 min of the submaximal exercise steps. The highest exercise intensity for each individual with a mean RER $<1$, during the final $3 \mathrm{~min}$, was chosen for the GE analysis. In this way, the highest possible GE was selected for every individual, because GE increases when exercise intensity rises, as can be seen in Fig. 1. The data of one of the subjects was excluded, because his mean RER during the final 3 min of the first submaximal exercise step $\left(45 \% \mathrm{PVO}_{2 \max }\right)$ already exceeded 1, which makes it impossible to calculate GE.

Repeated measures ANOVA revealed that there was no significant difference in $V_{2}$ between days $(F=1.28$, $p=0.29)$ and between different times of the day $(F=0.62$, $p=0.72)$. The variation in $V \mathrm{O}_{2}$ is displayed in Fig. 2a.

GE did not differ significantly between days $(F=2.70$, $p=0.08)$ or between different times of the day $(F=0.16$, $p=0.99$ ) (Fig. 2c), thus there was no least square Cosinor 


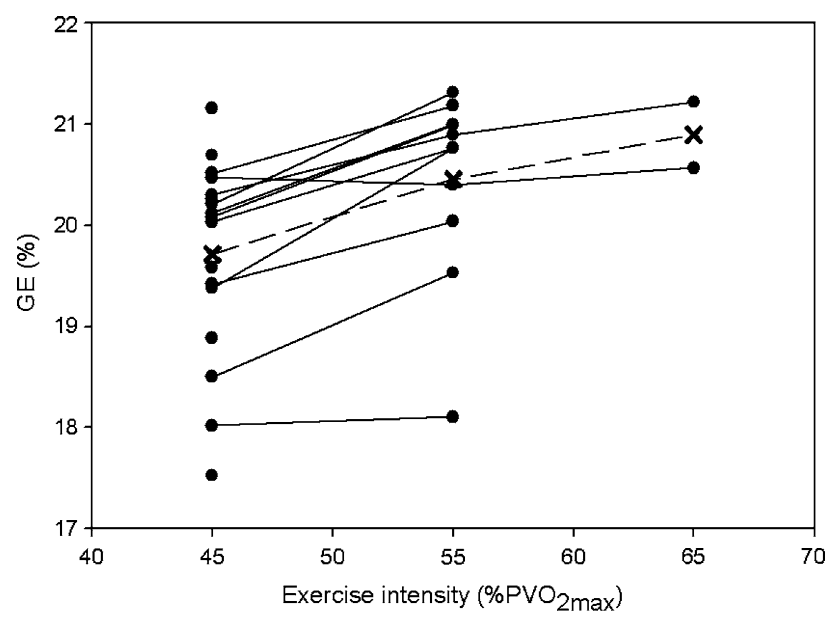

Fig. 1 The increase in gross efficiency $(G E)$ with exercise intensity $\left(\% \mathrm{PVO}_{2 \max }\right)$. Each data point represents the mean GE of 3 days for each individual. Data points were only displayed when RER did not exceed 1.0. Cross mark the overall mean GE. The highest intensity with valid data was selected for each subject

regression analysis performed. There were no significant interaction effects. The individual GE data is displayed in Fig. 3. To assess the variability in GE between days, i.e. the reliability, the $95 \%$ limits of agreement and the within subject CV were determined. At first, heteroscedasticity was examined by calculating the correlation coefficient between the absolute differences and the individual means. Of the 21 correlation coefficients only one correlation coefficient was significantly positive, besides which ten correlation coefficients were negative, from which could be concluded that there was no heteroscedasticity present in the data. The lower boundary of the $95 \%$ limits of agreement was $19.6 \%$ and the upper boundary was $20.8 \%$ for a mean GE of $20.2 \% \pm 0.15 \%$. The total CV was determined from the CVs at the six different times of the day with the following formula $\mathrm{CV}=\sqrt{ }\left(\left(\mathrm{CV}_{1}^{2}+\mathrm{CV}_{2}^{2}+\ldots\right.\right.$. $\left.\mathrm{CV}_{n-1}^{2}+\mathrm{CV}_{n}^{2}\right) / n$ ), which resulted in a total $\mathrm{CV}$ of $4.4 \%$.

The RPE scores did not change significantly between days $(F=1.62, \quad p=0.21)$; however, there was a significant time of day effect on RPE $(F=13.8$, $p<0.001)$. A significant interaction effect was found between day and time of day $(F=2.35, p<0.05)$. Post hoc analysis with a Bonferroni adjustment $(\alpha=0.017)$ showed that there was no significant time of day effect for day $1(F=2.21, p=0.05)$, but that there was a significant time of day effect for day $2(F=8.59, p<0.001)$ and day $3(F=12.56, p<0.001)$. However, the least square Cosinor regression analyses showed that the amplitudes of the best fit Cosinor functions did not differ significantly from zero $(F=1.00, p=0.40)$ (Fig. $2 b)$.

To investigate if possible circadian rhythms in physiological variables during exercise were due to changes in BT, BT was measured before and immediately after each exercise bout. It was not possible to perform a repeated measures ANOVA on BT data to test if BT changed significantly between different times of the day, because of missing values, which were caused by the premature excretion of the temperature pill in several subjects. To test if there existed a circadian rhythm in BT a least square Cosinor regression analysis was performed. A repeated measures ANOVA was executed to examine if the amplitudes of the best fit Cosinor functions differed significantly from zero $(F=55.4, p<0.001)$. Post hoc analysis with a Bonferroni adjustment $(\alpha=0.017)$ showed that the amplitude of the best fit Cosinor function of BT of day 1, day 2 , and day 3 were all significantly different from zero $(F=146, \quad p<0.001 ; \quad F=142, \quad p<0.001 ; \quad F=163$, $p<0.001$ ) (Table 1). There was no difference in the amplitude of the best fit Cosinor function of BT before and immediately after exercise $(F=0.30, p=0.59)$. The mean minimum BT was estimated to be $36.54 \pm 0.18^{\circ} \mathrm{C}$ for day 1 and was reached at 03:42 $\pm 3: 14 \mathrm{~h}$, the minimum BT was $36.6 \pm 0.21$ and $36.6 \pm 0.19^{\circ} \mathrm{C}$ during day 2 and 3 and was reached at $02: 46 \pm 6: 32$ and $03: 57 \pm 4: 31 \mathrm{~h}$, respectively. The maximum BTs were estimated to be $37.5 \pm 0.30,37.3 \pm 0.25$, and $37.3 \pm 0.18^{\circ} \mathrm{C}$, reached at $17: 07 \pm 3: 11, \quad 17: 35 \pm 1: 45$, and 17:22 $\pm 2: 13 \mathrm{~h}$, at, respectively, day 1 , day 2 , and day 3 . Immediately after the (a)

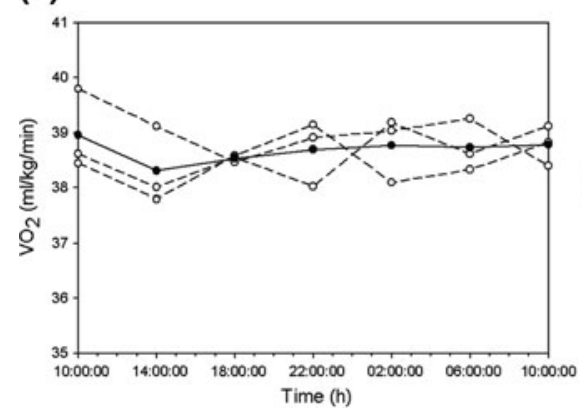

(b)

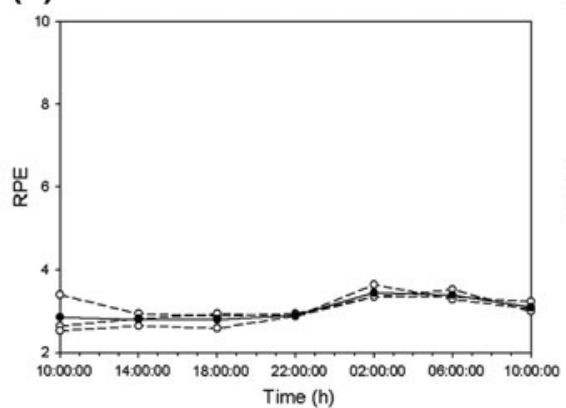

(c)

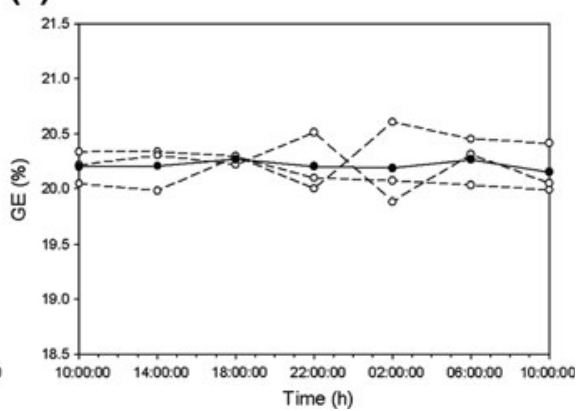

Fig. 2 The within day variation in $V \mathrm{O}_{2}(\mathbf{a}), \mathrm{RPE}(\mathbf{b})$, and $\mathrm{GE}$ (c) averaged over all subjects. The broken lines are the variation in $V \mathrm{O}_{2}$, $\mathrm{RPE}$, and GE within day 1,2 , and 3 . The solid line is the average of all 3 days 
(a)

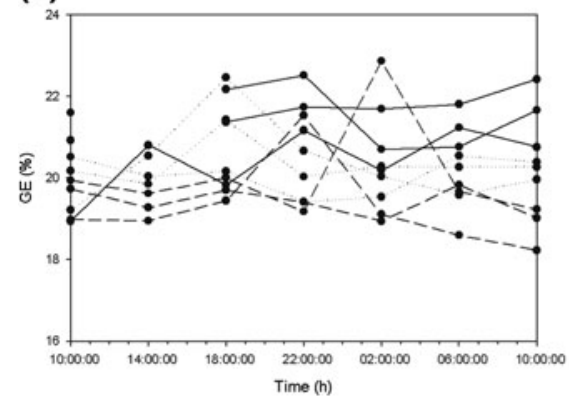

(d)

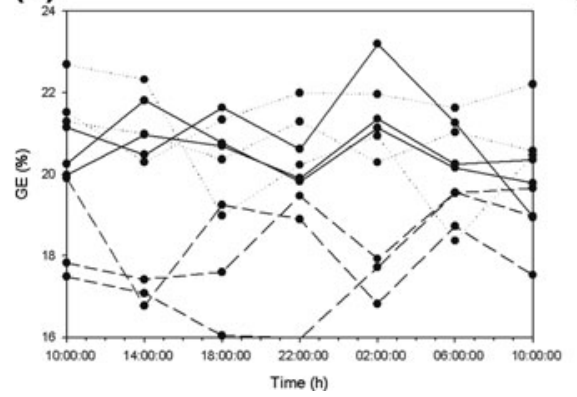

(b)

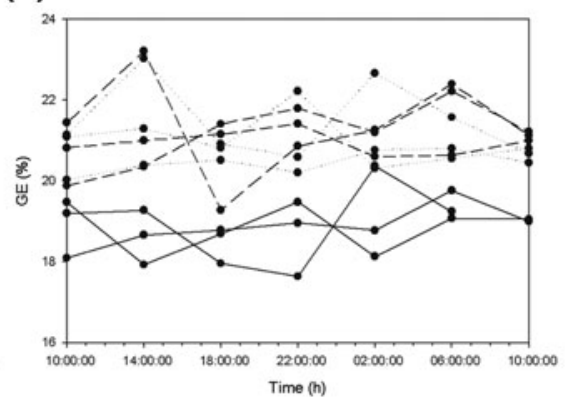

(e)

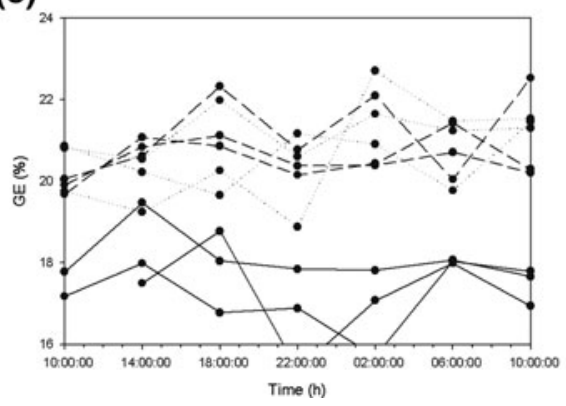

(c)

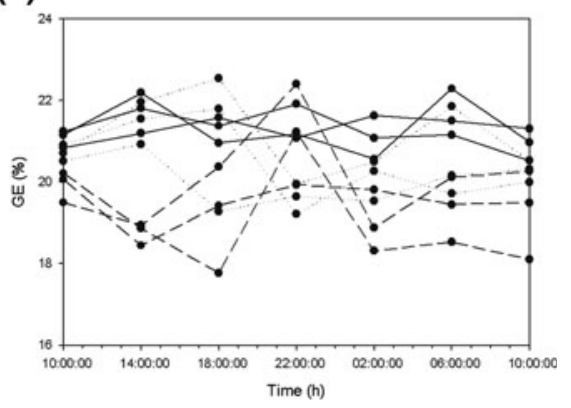

(f)

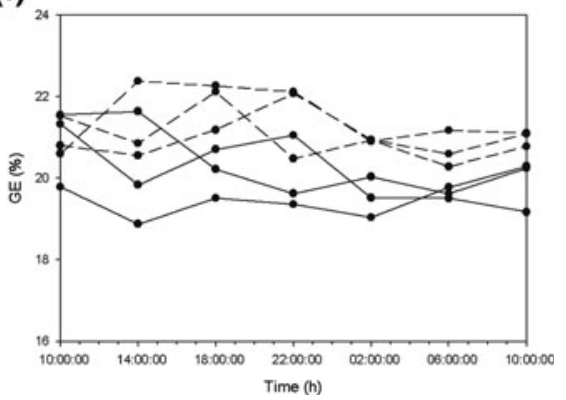

Fig. 3 The individual variation in GE. a-f show the individual variation in GE for subject A (solid lines), B (broken lines), and C (dotted lines), D-F, G-I, J-L, M-O, and P and Q, respectively, within day 1, 2 and 3

exercise bout the maximum BTs were $38.2 \pm 0.36$, $38.2 \pm 0.24$, and $38.2 \pm 0.27^{\circ} \mathrm{C}$, reached at $16: 26 \pm 3: 49$, 17:38 $\pm 4: 23$, and 17:12 $\pm 2: 56 \mathrm{~h}$, at, respectively, day 1 , day 2 , and day 3 (Fig. 4).

The scores on the LSEQ for the different days were significantly different from $50(F=6.76, p=0.001)$. The mean scores of the experimental testing days were $45.28 \pm 17.46,44.93 \pm 12.25$, and $44.05 \pm 12.15$, for day 1 , 2, and 3, respectively. Post hoc analysis with a Bonferroni adjustment $(\alpha=0.017)$ revealed that the LSEQ scores after a night sleep on day 1 did not significantly differ from $50(F=6.86, p=0.02)$. The LSEQ scores of day 2 and day 3 were significantly different from 50 $(F=19.1, p<0.05 ; F=23.1, p<0.001)$. There was no significant difference between the LSEQ scores on the three experimental testing days $(F=0.31, p=0.74)$, there was a significant difference between the scores on the ten questions $(F=7.78, p<0.001)$ and a significant interaction effect between days and questions $(F=1.66$, $p<0.05$ ). Subjects described falling asleep as more difficult, their quality of sleep as more restless, and they were more tired after waking up than after a normal night sleep.

\section{Discussion}

The purpose of the present study was to assess the variation in GE between and within days. The main outcome was that there was no significant difference in GE between days and between different times of the day.

Before the influence of different factors on GE can be studied, the smallest detectable change in GE must be known. Moseley and Jeukendrup (2001) investigated the reliability of cycling efficiency during a graded exercise test and found a CV of $4.2 \%$ for GE, from which they concluded that a graded exercise test using $35 \mathrm{~W}$ increments every 3 min resulted in reliable measures of GE and economy. Moseley and Jeukendrup (2001) calculated the within subject $\mathrm{CV}$ on the basis of three graded exercise tests. The design of the present study made it possible to determine the reliability of GE at six different times of the day, the reliability of GE at 10:00 $\mathrm{h}$ was based on six measurements and the reliability of GE at the other times of the day was based on three measurements. Even with the limitations of the study of Moseley and Jeukendrup (2001) the total within subject CV of $4.4 \%$ for GE found in this study was of the same magnitude as the CV of $4.2 \%$ for GE reported in the study of Moseley and Jeukendrup (2001). The mean CV in the present study was $3.9 \%$, which suggests that, for example, an improvement in GE from 20.2 to $21.0 \%$ can be reliably detected. However, the use of the $\mathrm{CV}$ assumes that heteroscedasticity is present in the data. From the correlation coefficients between absolute differences and individual means could be concluded that there was no heteroscedasticity present in the GE data of this study, which means that the CV is not the best measure to 
determine absolute reliability and that the $95 \%$ limits of agreement is potentially a better measure of reliability (Atkinson and Nevill 1998). Therefore, The 95\% limits of agreement were determined in the present study. With an overall mean GE of $20.2 \%( \pm 0.15 \%)$ the chance is $95 \%$ that a repeated GE measure would be between 19.6 and $20.8 \%$. Therefore, the smallest change in GE than can be detected is for example an increase as small as $0.6 \%$ in GE from 20.2 to $20.8 \%$ or a decrease from 20.2 to $19.6 \%$, which is in agreement with the results of Moseley and Jeukendrup (2001).

The existence of a possible circadian rhythm in GE, induced by changes in body temperature, was studied by determining GE at six time points equally distributed over the $24 \mathrm{~h}$ of the day. No significant difference in GE between different times of the day was found, which implies that there is no circadian rhythm in GE. This result supports the results of the study of Brisswalter et al. (2007), who found no significant difference in GE between submaximal exercise bouts at $80 \% \mathrm{PT}_{\text {vent }}$ in the morning and evening. However, Brisswalter et al. (2007) did find a significantly lower $\mathrm{VO}_{2}$ amplitude and smaller $\mathrm{VO}_{2}$ time constant in the evening, which resulted in a significantly higher $\mathrm{NE}$ in the

Table 1 Characteristics of the circadian rhythm in body temperature

\begin{tabular}{|c|c|c|c|c|c|c|c|c|c|}
\hline \multirow[t]{2}{*}{ Subject } & \multicolumn{3}{|c|}{ Day 1} & \multicolumn{3}{|c|}{ Day 2} & \multicolumn{3}{|c|}{ Day 3} \\
\hline & $M$ & $A$ & $\varphi$ & $M$ & A & $\varphi$ & $M$ & A & $\varphi$ \\
\hline A & 36.9 & 0.43 & 99.4 & 36.9 & 0.20 & 99.2 & 36.9 & 0.44 & 95.6 \\
\hline B & 37.1 & 0.53 & 99.2 & 36.8 & 0.40 & 99.0 & 36.9 & 0.57 & 99.1 \\
\hline C & 36.9 & 0.57 & 100.2 & 37.1 & 0.36 & 99.5 & 37.0 & 0.18 & 98.9 \\
\hline D & 36.8 & 0.35 & 98.8 & 36.9 & 0.50 & 99.1 & 36.8 & 0.38 & 99.2 \\
\hline E & 36.8 & 0.26 & 99.2 & 37.0 & 0.27 & 99.0 & 36.7 & 0.31 & 99.6 \\
\hline $\mathrm{F}$ & 37.1 & 0.52 & 99.3 & 37.3 & 0.16 & 101.5 & 36.9 & 0.44 & 99.5 \\
\hline G & 37.0 & 0.64 & 99.4 & 36.8 & 0.44 & 99.1 & 36.9 & 0.49 & 99.6 \\
\hline $\mathrm{H}$ & 37.3 & 0.72 & 99.4 & 37.0 & 0.53 & 99.5 & 37.1 & 0.40 & 99.1 \\
\hline I & 37.3 & 0.58 & 99.2 & 37.3 & 0.68 & 99.1 & 37.0 & 0.46 & 99.0 \\
\hline $\mathbf{J}$ & 37.1 & 0.41 & 99.7 & 36.9 & 0.37 & 99.3 & 37.0 & 0.35 & 99.5 \\
\hline $\mathrm{K}$ & 37.1 & 0.63 & 99.9 & 37.0 & 0.36 & 99.0 & 36.9 & 0.42 & 101.7 \\
\hline $\mathrm{L}$ & 36.7 & 0.35 & 98.9 & 36.8 & 0.44 & 99.1 & 36.8 & 0.51 & 98.9 \\
\hline M & 37.3 & 0.38 & 99.4 & 37.3 & 0.37 & 100.9 & 37.1 & 0.13 & 100.4 \\
\hline $\mathrm{N}$ & 36.8 & 0.20 & 99.7 & 36.7 & 0.18 & 99.0 & 36.7 & 0.10 & 100.7 \\
\hline $\mathrm{O}$ & 37.0 & 0.47 & 99.1 & 37.0 & 0.36 & 99.0 & 37.0 & 0.17 & 99.0 \\
\hline $\mathrm{P}$ & 37.0 & 0.32 & 99.2 & 36.8 & 0.32 & 99.5 & 36.8 & 0.30 & 99.3 \\
\hline Q & 36.7 & 0.50 & 99.5 & 36.7 & 0.48 & 99.7 & 36.8 & 0.29 & 99.1 \\
\hline Mean & 37.0 & 0.46 & 99.4 & 37.0 & 0.38 & 99.4 & 36.9 & 0.35 & 99.3 \\
\hline SD & 0.2 & 0.14 & 0.4 & 0.2 & 0.13 & 0.7 & 0.1 & 0.14 & 1.2 \\
\hline
\end{tabular}

Body temperature measured immediately before the start of the exercise test

$M$ the mesor (mean value), $A$ the amplitude (half the variation from peak to trough values), $\varphi$ the acrophase (time of peak) of the best fit cosine function evening. However, NE is not the most appropriate measure of efficiency as NE uses a baseline subtraction, which implies that resting metabolic rate is independent of exercise intensity and is totally isolated from work production (Ettema and Lorås 2009). Ettema and Lorås (2009) reviewed the available literature about cycling efficiency and concluded that it is not correct to believe that resting metabolic rate is unaffected by exercise intensity. Therefore, they recommended the use of GE as the most appropriate measure of whole body efficiency (Ettema and Lorås 2009). A minimum of six exercise bouts evenly distributed over the $24 \mathrm{~h}$ of the day is necessary to study circadian rhythms (Nelson et al. 1979). Reilly and Brooks (1990) used the minimum of six exercise bouts evenly distributed over the day, which led to the finding that during rest rectal temperature, $\mathrm{HR}, V_{2}, V \mathrm{CO}_{2}$, and $\mathrm{VE}$ possessed a circadian rhythm, but, that the circadian rhythm in $V \mathrm{O}_{2}, V \mathrm{CO}_{2}$, and VE disappeared when exercise intensity increased to submaximal and maximal workloads. The absence of a circadian rhythm in $V \mathrm{O}_{2}, V \mathrm{CO}_{2}$, and RER resulted in the absence of a circadian rhythm in GE, NE, and DE. The results of this study are in agreement with the results of Reilly and Brooks (1990). We found a circadian rhythm in resting $V_{2}$. However, this circadian rhythm was absent during exercise. The difference between the current study and the study of Reilly and Brooks (1990) is the chosen exercise intensity at which efficiency was determined. Reilly and Brooks (1990) determined GE at absolute workloads of 82 and $147 \mathrm{~W}$. However, to precisely determine GE each subject should exercise at multiple relative exercise intensities as GE increases with exercise intensity (Ransom et al. 2008). Another difference is that subjects in the study of Reilly and Brooks (1990) performed the exercise tests on six separate days and not on the same day, which potentially creates an extra source of variation. With this source of potential variation excluded by the design of the present study no circadian rhythm in GE was found.

All subjects were physically active and engaged in regular sport activities at least two times per week (7.25 $\pm 5.6 \mathrm{~h}$ /week). Eleven of the subjects were cyclists, they had at least 2 years of cycling experience and cycled minimally $3,000 \mathrm{~km}$ per year. The remaining subjects engaged in divergent sport activities. There was a significant difference in GE between cyclists and non-cyclists $(F=6.97, p<0.05)$, with the cyclists having a higher mean GE $(20.7 \% \pm 0.93 \%)$ than the non-cyclists $(19.4 \% \pm 1.71 \%)$ (Fig. 5a, b). There was no significant interaction effect between time of day and cyclist versus non-cyclist $(F=1.56, p=0.17)$. Thus, even well trained cyclists do not show a circadian rhythm in GE.

One of the shortcomings of the present study is the significant difference between the LSEQ scores of the subjects and 50, the score belonging to a normal night sleep 


\section{day 1}

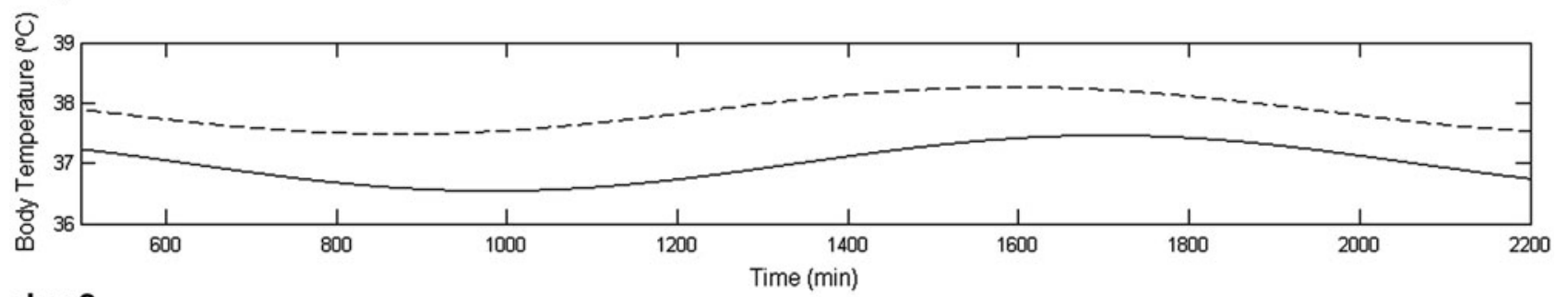

day 2

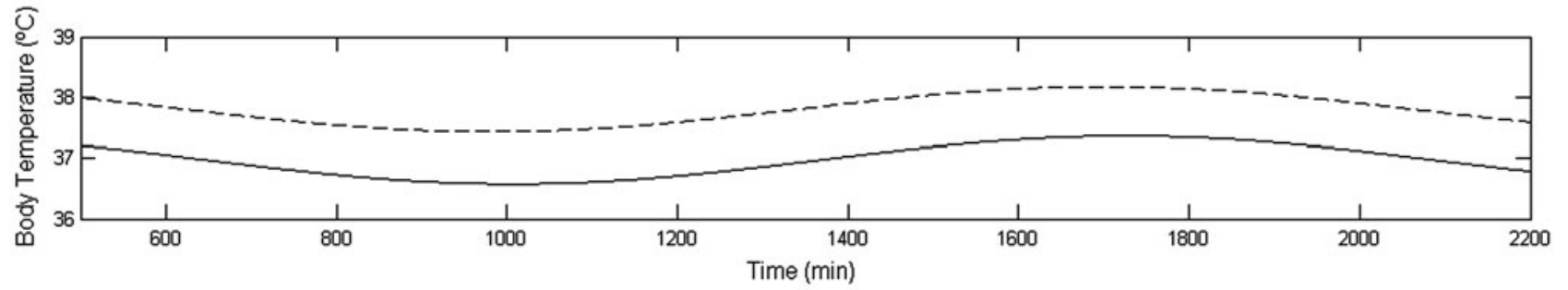

day 3

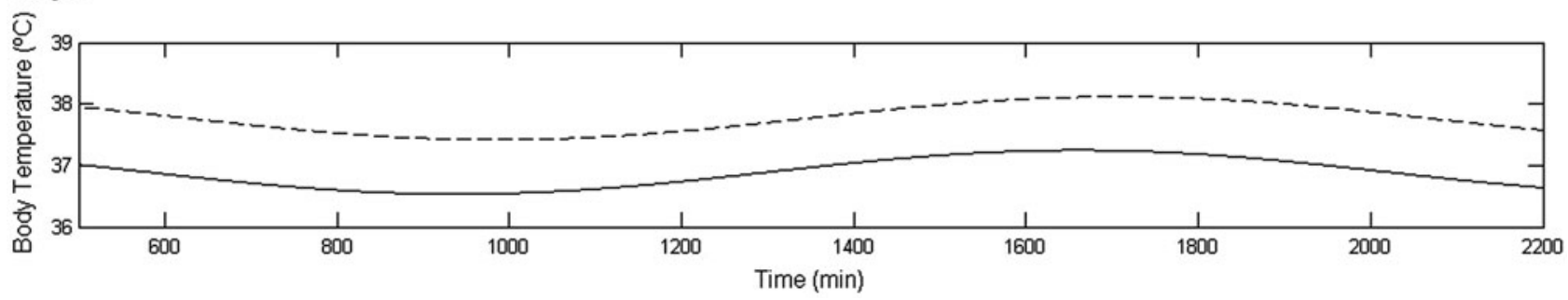

Fig. 4 The circadian rhythm in resting body temperature of day 1, day 2, and day 3. The solid and broken line are the circadian rhythms in, respectively, pre- and post-exercise body temperature

(a)

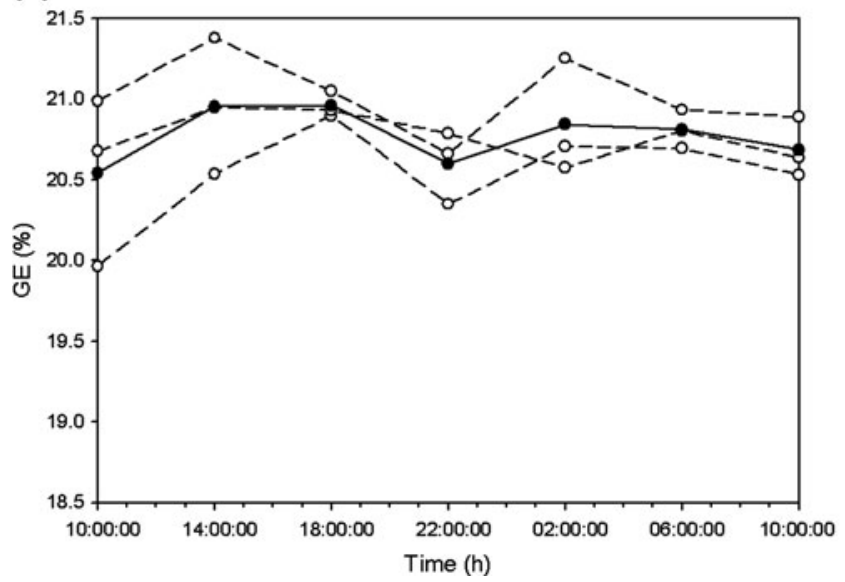

(b)

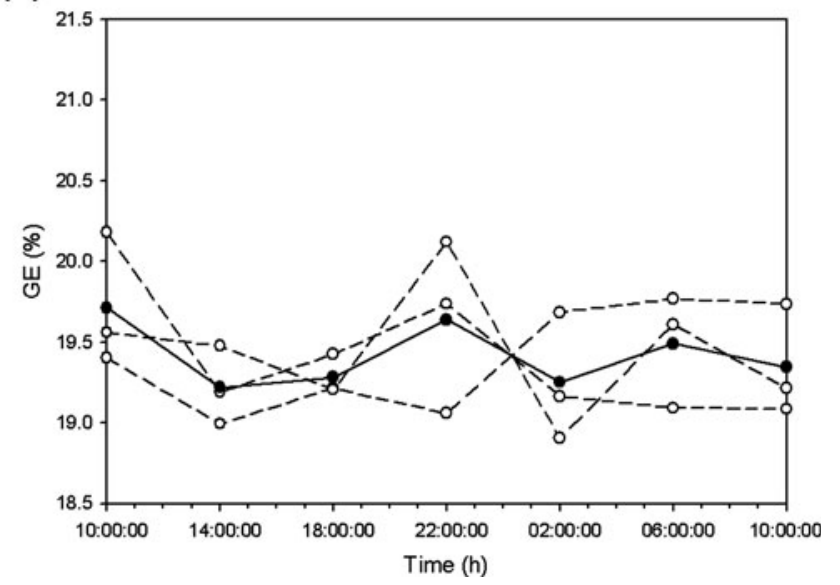

Fig. 5 The variation in gross efficiency (GE) over the day of cyclists (a) and non-cyclists (b). The broken lines are the variation in GE within day 1,2 , and 3 . The solid line is the average of all 3 days

(Lomeli et al. 2007), for day two and three. However, there were no significant differences in the data collected during the first submaximal exercise test and during the last submaximal exercise test, both conducted at the same time of day, namely 10:00 h. This suggests that there was no effect of fatigue. Besides that, the advantage of the chosen protocol in the current study is the standardization of the experimental conditions, i.e., food intake, the consumption of beverages, and sleep were controlled in the same way during the three experimental testing days. Thus, the influence of confounding factors on GE was minimized during the experimental testing days. Whether because of 
or in spite of these experimental controls, the data support the concept that GE is a very robust measurement which, if performed according to clearly defined rules, is remarkably robust. Both our data and the data of others (where some experimental controls were not as rigid) (Reilly and Brooks 1990; Moseley and Jeukendrup 2001) suggest that the within subject variation in GE across multiple measurements and across the time span of the entire day is $<1.0 \%$. Compared to the often cited $3-7 \%$ day to day variation in other index physiological parameters such as $V \mathrm{O}_{2 \max }$ (Reilly and Brooks 1990), these data suggest that GE is remarkably resistant to perturbing influences.

In summary, it can be concluded that GE is a very robust measure. An increase or decrease in GE as small as $0.6 \%$ can be reliably detected and circadian rhythms in BT and resting $V \mathrm{O}_{2}$ do not result in a circadian rhythm in GE, determined at an exercise intensity with RER close to 1.00, so long as constraints related to steady-state $\mathrm{VO}_{2}$ and RER are observed.

Open Access This article is distributed under the terms of the Creative Commons Attribution Noncommercial License which permits any noncommercial use, distribution, and reproduction in any medium, provided the original author(s) and source are credited.

\section{References}

Atkinson G, Nevill AM (1998) Statistical methods for assessing measurement error (reliability) in variables relevant to sports medicine. Sports Med 26(4):217-238

Barstow TJ, Molé PA (1991) Linear and nonlinear characteristics of oxygen uptake kinetics during heavy exercise. J Appl Physiol 71(6):2099-2106

Bell MP, Ferguson RA (2009) Interaction between muscle temperature and contraction velocity affects mechanical efficiency during moderate-intensity cycling exercise in young and older women. J Appl Physiol 107:763-769

Borg GA (1982) Psychophysical bases of perceived exertion. Med Sci Sports Exerc 14(5):377-381

Brisswalter J, Bieuzen F, Giacomoni M, Tricot V, Falgairette G (2007) Morning-to-evening differences in oxygen uptake kinetics in shortduration cycling exercise. Chronobiol Int 24(3):495-506

Callard D, Davenne D, Gauthier A, Lagarde D, van Hoecke J (2000) Circadian rhythms in human muscular efficiency: continuous physical exercise versus continuous rest. A crossover study. Chronobiol Int 17(5):693-704

Callard D, Davenne D, Lagarde D, Meney I, Gentil C, Van Hoecke J (2001) Nycthemeral variations in core temperature and heart rate: continuous cycling exercise versus continuous rest. Int $\mathrm{J}$ Sports Med 22(8):553-557

Coast JR, Cox RH, Welch HG (1986) Optimal pedalling rate in prolonged bouts of cycle ergometry. Med Sci Sports Exerc 18(2):225-230

Coyle EF, Feltner ME, Kautz SA, Hamilton MT, Montain SJ, Baylor AM, Abraham LD, Petrek GW (1991) Physiological and biomechanical factors associated with elite endurance cycling performance. Med Sci Sports Exerc 23(1):93-107

Coyle EF, Labros SS, Horowitz JF, Beltz JD (1992) Cycling efficiency is related to the percentage of type I muscle fibers. Med Sci Sports Exerc 24(7):782-788 de Koning JJ, Bobbert MF, Foster C (1999) Determination of optimal pacing strategy in track cycling with an energy flow model. J Sci Med Sport 2(3):266-277

de Koning JJ, Foster C, Lampen J, Hettinga F, Bobbert MF (2005) Experimental evaluation of the power balance model of speed skating. J Appl Physiol 98(1):227-233

Deschenes MR, Sharma JV, Brittingham KT, Casa DJ, Armstrong LE, Maresh CM (1998) Chronobiological effects on exercise performance and selected physiological responses. Eur J Appl Physiol Occup Physiol 77:249-256

Ettema G, Lorås HW (2009) Efficiency in cycling: a review. Eur J Appl Physiol 106(1):1-14 (Epub ahead of print)

Faria IE, Drummond BJ (1982) Circadian changes in resting heart rate and body temperature, maximal oxygen consumption and perceived exertion. Ergonomics 25(5):381-386

Ferguson RA, Ball D, Sargeant AJ (2002) Effect of muscle temperature on rate of oxygen uptake during exercise in humans at different contraction frequencies. J Exp Biol 205:981-987

Foss $\varnothing$, Hallén J (2005) Cadence and performance in elite cyclists. Eur J Appl Physiol 93:453-462

Foster C, Lucia A (2007) Running economy. The forgotten factor in elite performance. Sports Med 37(4-5):316-319

Garby L, Astrup A (1987) The relationship between the respiratory quotient and the energy equivalent of oxygen during simultaneous glucose and lipid oxidation and lipogenesis. Acta Physiol Scand 129(3):443-444

Giacomoni M, Bernard T, Gavarry O, Altare S, Falgairette G (1999) Diurnal variations in ventilatory and cardiorespiratory responses to submaximal treadmill exercise in females. Eur J Appl Physiol 80:591-597

He ZH, Bottinelli R, Pellegrino MA, Ferenczi MA, Reggiani C (2000) ATP consumption and efficiency of human single muscle fibers with different myosin isoform composition. Biophys $\mathrm{J}$ 79(2):945-961

Hettinga FJ, de Koning JJ, de Vrijer A, Wust RC, Daanen HA, Foster C (2007) The effect of ambient temperature on gross-efficiency in cycling. Eur J Appl Physiol 101(4):465-471

Hill DW (1996) Effect of time of day on aerobic power in exhaustive high-intensity exercise. J Sports Med Phys Fitness 36:155-160

Hintzy F, Mourot L, Perrey S, Tordi N (2005) Effect of endurance training on different mechanical efficiency indices during submaximal cycling in subjects unaccustomed to cycling. Can J Appl Physiol 30(5):520-528

Hopker JG, Coleman DA, Wiles JD (2007) Differences in efficiency between trained and recreational cyclists. Appl Physiol Nutr Metab 32(6):1036-1042

Hopkins WG (2000) Measures of reliability in sports medicine and science. Sports Med 30(1):1-15

Horne JA, Östberg O (1976) A self-assessment questionnaire to determine morningness eveningness in human circadian rhythms. Int J Chronobiol 4:97-110

Ingham SA, Whyte GP, Pedlar C, Bailey DM, Dunman N, Nevill AM (2008) Determinants of $800-\mathrm{m}$ and $1500-\mathrm{m}$ running performance using allometric models. Med Sci Sports Exerc 40(2): 345-350

Joyner MJ (1991) Modeling: optimal marathon performance on the basis of physiological factors. J Appl Physiol 70(2):683-687

Joyner MJ, Coyle EF (2008) Endurance exercise performance: the physiology of champions. J Physiol 586(1):35-44

Lomeli HA, Pérez-Olmos I, Talero-Gutiérrez C, Moreno CB, González-Reyes R, Palacios L, de la Peña F, Muñoz-Delgado J (2008) Sleep evaluation scales and questionnaires: a review. Actas Esp Psiquiatr 36(1):50-59

Lucia A, Hoyos J, Perez M, Santalla A, Chicharro JL (2002) Inverse relationship between $V \mathrm{O}_{2 \max }$ and economy/efficiency in worldclass cyclists. Med Sci Sports Exerc 34(12):2079-2084 
Mogensen M, Bagger M, Pedersen PK, Fernström M, Sahlin K (2006) Cycling efficiency in humans is related to low UCP3 content and to type I fibres but not to mitochondrial efficiency. J Physiol 15:669-681

Moseley L, Jeukendrup AE (2001) The reliability of cycling efficiency. Med Sci Sports Exerc 33(4):621-627

Nelson W, Tong YL, Lee JK, Halberg F (1979) Methods for Cosinorrhythmometry. Chronobiologia 6:305-323

Nickleberry BLJ, Brooks GA (1996) No effect of cycling experience on leg cycle ergometer efficiency. Med Sci Sports Exerc 28(11):1396-1401

Parrott AC, Hindmarch I (1980) The Leeds Sleep Evaluation Questionnaire in psychopharmacological investigations-a review. Psychopharmacology (Berl) 71(2):173-179
Ransom V, Clark A, van Langen FA, Uitslag TP, Hettinga FJ, de Koning JJ, Foster C (2008) Constant value of gross mechanical efficiency at high exercise intensity. Med Sci Sports Exerc 40(5):S67

Reilly T, Brooks GA (1990) Selective persistence of circadian rhythms in physiological responses to exercise. Chronobiol Int 7(1):59-67

Souissi N, Gauthier A, Sesboüé B, Larue J, Davenne D (2004) Circadian rhythms in two types of anaerobic cycle leg exercise: force-velocity and 30-s Wingate tests. Int J Sports Med 25:14-19

van Ingen Schenau GJ, Cavanagh PR (1990) Power equations in endurance sports. J Biomech 23(9):865-881

Whipp BJ, Wasserman K (1972) Oxygen uptake kinetics for various intensities of constant-load work. J Appl Physiol 33(3):351-356 